\title{
Influence of a shop floor management system on labour productivity in an automotive parts manufacturing organisation in South Africa
}

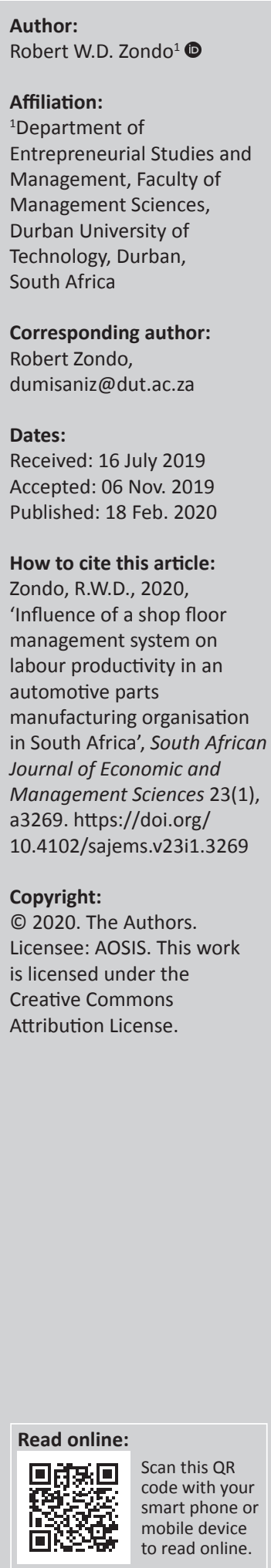

Background: South Africa's labour productivity at the shop floor remains an issue of central concern for business. It plays a role in the life of every person and the performance of every business, thus requiring the business to solve problems at the shop floor level. This sentiment underpins the concept of a shop floor management (SFM) system. An SFM system refers to the extent of control exercised at the shop floor level for commitment and involvement of shop floor employees aimed at improving productivity. It is a process that facilitates employee engagement.

Aim: This study examines the influence of an SFM system for productivity improvement in automotive parts manufacturing companies in South Africa. Productivity in the South African's manufacturing sector is low compared to its counterpart industries in the Asian and Western countries. This sector experiences the lack in short to medium term growth in productivity.

Setting: The automotive parts manufacturing company that has adopted an SFM strategy for productivity improvement participated in the study.

Methods: The study objectives were achieved by examining the production and related experiences in the company. The collection of data was carried out in two phases. This includes the collection of results pre and post-SFM implementation from company records for spoilage, absenteeism and housekeeping rates. The pre-SFM results were quarterly data reflecting the company's performance over the three-year period prior to the implementation of the SFM. This company operates in the eThekwini District Municipality in KwaZulu-Natal.

Results: The study established that housekeeping and SFM have no relation to labour productivity. However, it revealed the relationship of both absenteeism and spoilage rates with labour productivity.

Conclusion: SFM is an employee engagement process that creates a working environment that encourage worker participation and commitment.

Contribution: The original value of this paper is its approach in uncovering strengths and weaknesses of SFM for productivity in South Africa.

Keywords: Automotive parts manufacturing organisation; employee shop floor engagement; employee motivation; labour productivity; shop floor management.

\section{Introduction}

South Africa's labour productivity, in the manufacturing sector, is low when compared to Korea, the United States of America (USA), Taiwan, Japan, France and the United Kingdom (UK) (Klein 2012). It lacks both short- and long-term growth in productivity (UNIDO 2013). The South African manufacturing industry only achieved 36\% of the USA productivity level in 2014 (Conference Board 2015). Hence, this study investigates whether the shop floor management (SFM) strategy has the ability to improve productivity in the selected automotive parts manufacturing company.

Scholars have described the SFM system in different ways. Hanenkamp (2013) defined it as a process designed to empower the workforce so that they make decisions and solve problems appropriate to their level in the organisation. The logic is that the people closest to a problem or opportunity are in the best position to make decisions for improvement if they have control of the improvement process. According to Suzaki (1993) (a Japanese employee engagement philosopher), 
SFM is a practice of three reals (that is, Genba, Genbutsu and Genjitsu). Genba refers to the real place or the location where the value is created, while Genbutsu refers to all those associated to understand the nature of all problems. Genjitsu is the third real that draws a connection between the current problems and the root causes. Thus, Suzaki (1993) defines SFM as a closed loop process that helps observe problems on site and eliminate the root causes of such problems. In return, this will have a positive impact on productivity. A slightly different approach sees Peters (2003) explaining SFM as the focus on the lower levels (namely the shop floor operators) to react quickly to process failures. Hanenkamp (2013) justifies the above explanation by stating that the empowered shop floor teams with profound understanding of shop floor standards and targets sustain the business's attempt to remain competitive and profitable.

Womack (2008) indicates that SFM is not literally mentioned in the earlier versions of the Toyota house of lean principles. However, there are several connections between the Toyota lean principles and SFM, which include developing and managing shop floor operations and workers. According to Hertle et al. (2016), SFM is one of the major management approaches in lean production. Through activating the potentials of employees, SFM aims to improve the business processes by developing the competencies of the employees (Hertle et al. 2016). Hence, this study examines the influence of SFM on labour productivity in automotive parts manufacturing businesses.

Larteb, Benhadou, Haddout and Nahla (2016), who referred to SFM as shop floor control (SFC), indicate that the key to lean performance is through the implementation of a daily SFC system. They mention that SFC enhances process improvement in all sectors of the industrial economy. In order for companies to succeed and enhance their productivity, daily contact with the shop floor is vital. Hence, this study is guided by the following two research questions (RQ):

- RQ1: Is SFM an appropriate system for productivity improvement?

- RQ2: Does control at shop floor level improve employee commitment for productivity increase?

For an organisation to evolve, people working within it have to be involved in processes that improve the organisation's productivity (Business Victoria 2016). The people-involving initiative of SFM is employee engagement. Thus, shop floor employee engagement is a psychological and physical demonstration of what the employee understands of their role in the organisation, and the commitment of stewardship that manifests in high productivity levels in their work (Geldenhuys, Laba \& Venter 2014). Employees that engage with their organisations and those that feel a sense of belonging remain loyal and concern themselves with productivity in their roles (Guest 2014). Despite the acknowledgement of its importance in business, low levels of shop floor employee engagement are reported globally. The percentage of highly-engaged shop floor employees is reported to be $13 \%$. However, $26 \%$ are reported to be disengaged (Illing 2012). Bersin (2015) lists the elements that negatively affect shop floor employee engagement as an absence of meaningful work, a less inclusive workplace and a disregard for opportunities for growth. Employees should be recognised as a company's most important resource and a driver for changing processes within the production area (Röhrle 2009). Therefore, the employee potentials should be utilised and appropriately developed (Grundnig \& Meitinger 2013). This process will lead to the shift of decision rights from supervisors to employees. Managers will then act as coaches to train employees in methodical aspects of their work. Subsequently, this enhances productivity at the shop floor level. Various studies show a positive correlation between high levels of shop floor employee engagement and productivity (Gallup 2016; Guest 2014). However, previous studies (Dobre 2013; Illing 2011; Polster 2013) have not shown the effectiveness of an SFM system as an intervening variable for productivity in the automotive manufacturing industry in South Africa.

The next section discusses the theoretical framework of the study. It elaborates on an overview of SFM, as well as the effects of shop floor processes through housekeeping. A discussion of SFM and labour productivity concludes the literature review of the study. The research methodology exploring the research design, data collection, as well as the measurement and data analysis discusses the approach employed in the study. Study results, followed by the related discussion, implications of results for policy and practice, study limitations and future studies required, conclude the article.

\section{Literature review}

This section discusses an overview of SFM. It discusses the effects of shop floor processes through housekeeping. The section elaborates on SFM and labour productivity, and presents SFM as a process for employee engagement. Exploration of employee motivation and teamwork as SFM tools concludes the section.

\section{Overview of shop floor management}

Shop floor management has been described as a system that provides a bottom-up information flow in production with the use of key performance indicators, action plans and regular short meetings at the shop floor. According to Hanenkamp (2013), the objective of SFM includes the development of empowered shop floor teams. Each team consists of operators and the team leader of that specific work area. Hertle et al. (2016) indicate that the process starts with grouping the workforce into teams and allowing the team to track their contribution to the organisation's key performance indicators (KPIs). During this process, shop floor employees express themselves physically, cognitively and emotionally during role performance (Gems 2015). Dobre (2013) defined SFM's engagement process as a positive, fulfilling, work-related state of mind that is characterised by 
vigour, dedication and absorption. Hence, Cherry (2016) defined it as the level of commitment and the involvement an employee has towards their organisation and its values. Hoxsey (2010) studied the relationship between employee engagement within the SFM system, the organisational commitment and absenteeism. He indicates that, by looking at employees' absenteeism records, an organisation could pinpoint which employees may not be committed in their current job. When a member of staff is unexpectedly absent from work, it raises immediate cause for concern with regard to the likelihood of missing deadlines, disruption to the quality and continuity of service delivery, the loss of productivity and efficiency, as well as a drop in motivation. Consequently, this study assesses the influence of SFM on absenteeism for labour productivity.

Mann (2009) explains that the process of SFM is comprised of core shop floor elements. These include the use of visual controls in which visual aids in the form of process performance charts illustrate the department's performance. It involves the initiation of daily team meetings to provide feedback to the department using visual aids, as well as the standard accountability processes. Hence, team leaders should be trained with skills necessary for the management of shop floor employees (Hanenkamp 2013). Illing (2011) adds that SFM empowers companies to implement a sustainable continuous improvement process, complements it with the integrated production systems in order to bring executives closer to their daily business, creates transparency, and focuses on responsibilities. Similarly, Illing (2012) indicates that SFM has a positive influence on labour productivity. It provides the workforce with clear direction and goals, unites the organisation in one direction, initiates feedback forums which focus on the current problems and seeks solutions to resolve these problems, promotes involvement from management with shop floor employees, and fosters an environment for mutual trust and respect. Hertle et al. (2016) stress that the entire SFM process depends heavily on employee engagement philosophy. Thus, employee engagement is a positive attitude held by the employee towards the organisation and its value (Mann 2009). An engaged employee is aware of business context and works with colleagues to improve performance within the job for the benefit of the organisation. As a driver of an SFM system, Wranx (2016) adds that employee engagement is a positive, fulfilling, work-related state of mind that is characterised by vigour, dedication and absorption.

\section{The effects of shop floor processes through housekeeping}

Two significant challenges in business, such as competitiveness and efficiency, have impelled a number of manufacturing organisations to implement innovative management strategies (Zahraee et al. 2014). This includes housekeeping strategies like 5S. The 5S (or good housekeeping) involves the principle of waste elimination through workplace organisation (Dobre 2013). It applies standard housekeeping practices in the workplace through the five principles of sort, set in order, clean, standardise and sustain (Harino 1996). For SFM to be effective, the $5 S$ approach must guide shop employees towards their work and help improve communication among various business functions and departments. A well-organised workplace provides a safe and efficient production environment, which boosts shop floor employee morale, promoting the feeling of ownership, pride and ownership of their responsibilities. Many researchers (Bicheno 1998; Hirano 1996; Ho 1997; O'hEocha 2000) believe that the successful implementation of $5 S$ in the SFM environment significantly improved quality, productivity, time delivery, safety and shop floor employee morale values.

\section{Shop floor management and labour productivity}

An engaged employee is able to offer a sustained effort to their organisation (Cook 2008). The benefits of shop floor employee engagement include improved labour productivity and greater passion for commitment to vision, strategy and goals of the organisation. Consequently, Dobre (2013) adds that SFM (as a primary process for employee engagement) is an approach that ensures the effective utilisation of people and processes. Employee engagement through SFM team meetings is key to achieving labour productivity targets outlined by the business. The business needs to foster a shop floor culture that encourages the workforce to perform their responsibilities to meet customer expectations, thus positively influencing labour productivity (Dobre 2013). According to Hanenkamp (2013), for employees to perform optimally they should understand their work standards, receive adequate training and be provided with timely feedback regarding their performance (Dobre 2013). Wranx (2016) adds that employees operating in an SFM environment must be engaged in order to yield greater labour productivity. For labour productivity to be realised, Hanenkamp (2013) presents the links between SFM and employee motivation and teamwork.

\section{Employee motivation}

The motivational functions in performance feedback stipulate that management hold regular meetings to provide feedback regarding employee progress towards targets (Mann 2009). In this case, the feedback is used as an opportunity to appraise the employee for the purpose of increased efficiency, productivity and morale. Hence, the feedback process brings the opportunity to focus on work activities and targets. It encourages and motivates employees to perform better (Nyaoga, Simeon \& Magutu 2010).

\section{Teamwork}

A team is a collection of individuals who are interdependent in their tasks and share the responsibility for outcomes (Cohen \& Bailey 1997). Brown (1995) adds that teamwork can influence performance results and organisational objectives. It enhances effectiveness and productivity of a company, which leads to an organisation becoming more profitable (Jiang 2010). Hanenkamp (2013) indicates that empowered shop floor 
teams are important factors for successful SFM. The influence of teamwork is evident when employees come together during their daily team meetings (Quddus \& Nazmul 2014). The team is able to detect deviations, analyse and solve them in accordance with defined improvement measures. The implementation of the improvement measures is discussed in the structured meetings at the shop floor level (Illing 2011). However, Liker (2012) indicates that the problem and the implementation of the improvement measures can be escalated to the next level, upwards, depending on the complexity of the problem. Nonetheless, high performance work teams operate with little or no supervision (Bhuvanaiah \& Raya 2014). Hence, Illing (2012) indicates that SFM creates a platform in which team members are encouraged to share workloads and help each other. While SFM supports lean principles, the system improves the operational performance of a company. Therefore, a quantitative goal of SFM is the systematic control and improvement of operational KPIs (Peters 2003). These include quality, efficiency, and reliability of order fulfilment (Riegger 2011). Hence, this study investigates whether SFM has the ability to improve labour productivity in the automotive parts manufacturing sector. It explores the suitability of SFM as an appropriate tool for productivity improvement.

Hypothesis: The study is based on the following assumptions:

H1: The implementation of SFM leads to labour productivity improvement in automotive parts manufacturing companies.

$\mathbf{H 1}_{\mathbf{0}}$ : The implementation of SFM does not lead to labour productivity improvement in automotive parts manufacturing companies.

The following are sub-hypotheses:

H2: An increase in the absenteeism rate increases labour productivity in automotive parts manufacturing companies.

$\mathbf{H 2}$ : An increase in the absenteeism rate decreases labour productivity in automotive parts manufacturing companies.

H3: An increase in spoilage rate increases labour productivity in automotive parts manufacturing companies.

H3 $_{0}$ : An increase in spoilage rate decreases labour productivity in automotive parts manufacturing companies.

H4: An increase in the rate of housekeeping increases labour productivity in automotive parts manufacturing companies.

H4 $4_{0}$ An increase in the rate of housekeeping decreases labour productivity in automotive parts manufacturing companies.

\section{Methodology}

The method for this research will be discussed under the following headings: research design and approach, company that participated in the study, data collection, as well as measurement and data analysis.

\section{Research design and approach}

This study was quantitative in nature. It examines the relationship of labour productivity as a dependent variable with absenteeism, spoilage, and housekeeping as well as a post-SFM dummy. Bryman and Bell (2007) explain that the quantitative approach involves the use of statistical procedures to analyse the data collected. Consequently, after the measurements of the relevant variables, the scores were transformed using statistical methods. The study was also conclusive in design. Conclusive studies are meant to provide information that is useful in decision-making (Yin 2008).

\section{Company that participated in the study}

A convenience sample from one large automotive parts manufacturing organisation situated within the eThekwini District Municipality in the province of KwaZulu-Natal in South Africa was used. The company had adopted an SFM strategy and agreed to participate in the study. It is labour intensive and, prior to SFM implementation, disturbances were reported in the production process, resulting in the production targets not being met. The shop floor employees did not show commitment in their work activities. Consequently, the company had to implement SFM in order to improve supervision and give employees the platform to raise concerns they come across in their workplace. Hence, the SFM system was used on the company's blue-collar employees whose jobs require manual labour. The company had 1307 employees and operates a three-shift system. Table 1 presents a percentage breakdown of employees in terms of their level of activities.

\section{Data collection}

The collection of data from the company that participated in the study was carried out in two phases. This involved the collection of pre-and post-SFM results from company records for absenteeism, spoilage, housekeeping and labour productivity. The pre-SFM results were quarterly data reflecting the company's performance over the four-year period prior to SFM implementation. This includes data from the first quarter of 2009 to the final quarter of 2012. The postSFM data reflect the company's performance for four years after SFM was implemented. This includes data from the first quarter of 2014 to the final quarter of 2017. Note that the year 2013 was the SFM implementation period. Its data was excluded from the study.

\section{Measurement and data analysis}

The company's quarterly time series data on absenteeism, spoilage and housekeeping rates were used. The measurements were based on a total of 96 observations. A dummy variable, which assumed the value of 0 and 1 to

TABLE 1: Percentage breakdown of employees in terms of their level of activities.

\begin{tabular}{llc}
\hline Number & Level of activity & $\%$ \\
\hline 1. & Plant management & 3.1 \\
2. & Support administration staff & 11.0 \\
3. & Team leaders & 5.2 \\
4. & Line functional employees & 80.7 \\
\hline
\end{tabular}


represent the periods pre- and post-SFM, was introduced into the ordinary least squares (OLS) model. The aim was to isolate productivity effects resulting from an introduction of SFM. Consequently, if SFM proved to be a useful strategy in raising productivity levels, this would result in a statistically significant coefficient on the dummy variable.

The OLS model used was as follows: Labour Productivity $=\mathrm{B}_{0}$ $+\mathrm{B}_{1}$ Absenteeism $+\mathrm{B}_{2}$ Spoilage $+\mathrm{B}_{3}$ Housekeeping $+\mathrm{B}_{4}$ Pre/Post Dummy.

The above model identifies labour productivity as a function of absenteeism, the spoilage and housekeeping rates, as well as the SFM system.

For this study to achieve its objectives, the normality test was conducted using Kolmogorov-Smirnov and Shapiro-Wilk for the overall score of the constructs. Table 2 presents results for normality tests for labour productivity, absenteeism and spoilage rates, as well as the housekeeping rate.

The statistical tests in Table 2 show that the data were not normally distributed $(p>0.05)$. Hence, the results were analysed using a parametric test, that is, the $t$-tests.

\section{Study results}

This section presents results for the pre- and post-SFM means comparison, as well as labour productivity.

\section{Pre- and post-shop floor management means comparison}

Table 3 compare the means (in percentages) for absenteeism, spoilage and housekeeping.

Table 3 indicates that the percentage mean data for the preSFM period for absenteeism, spoilage and housekeeping are 2.51, 2.04 and $73.75 \%$. However, the percentage mean data for the post-SFM period for absenteeism, spoilage and housekeeping are $4.11,0.70$ and $65.04 \%$. The table shows

\begin{tabular}{|c|c|c|c|c|c|c|c|}
\hline \multirow[t]{2}{*}{ Variable } & \multicolumn{4}{|c|}{ Kolmogorov-Smirnov $\dagger$} & \multicolumn{3}{|c|}{ Shapiro-Wilk } \\
\hline & Group & Statistic & $d f$ & Sig. & Statistic & $d f$ & Sig. \\
\hline \multirow[t]{2}{*}{ Absenteeism rate } & 0 & 0.276 & 16 & 0.074 & 0.854 & 16 & 0.105 \\
\hline & 1 & 0.122 & 16 & 0.200 & 0.979 & 16 & 0.956 \\
\hline \multirow[t]{2}{*}{ Spoilage rate } & 0 & 0.218 & 16 & 0.200 & 0.952 & 16 & 0.730 \\
\hline & 1 & 0.315 & 16 & 0.019 & 0.830 & 16 & 0.059 \\
\hline \multirow[t]{2}{*}{ Housekeeping rate } & 0 & 0.230 & 16 & 0.200 & 0.912 & 16 & 0.366 \\
\hline & 1 & 0.246 & 16 & 0.166 & 0.862 & 16 & 0.124 \\
\hline
\end{tabular}

$d f$, degrees of freedom; Sig., significance.

$\dagger$, Lilliefors significance correction.

\begin{tabular}{llccc}
\multicolumn{4}{l}{ TABLE 3: } & Pre- and post-shop floor management percentage means comparison. \\
\hline Number & Variable & $\begin{array}{c}\text { Pre-SFM } \\
\text { period (\%) }\end{array}$ & $\begin{array}{c}\text { Post-SFM } \\
\text { period (\%) }\end{array}$ & $\begin{array}{c}\text { \% Mean difference } \\
\text { (pre - post) }\end{array}$ \\
\hline 1. & Absenteeism & 2.51 & 4.11 & -1.6 \\
2. & Spoilage & 2.04 & 0.70 & +1.37 \\
3. & Housekeeping & 73.75 & 65.04 & +8.71 \\
\hline
\end{tabular}

SFM, Shop floor management. mixed results of mean values on the three variables (that is, the absenteeism, spoilage and housekeeping from pre-SFM mean data to post-SFM mean data). Hence, the next section assesses labour productivity results as a consequence of SFM implementation.

\section{Labour productivity results}

Table 4 presents the results for labour productivity as a dependent variable to absenteeism, spoilage, housekeeping, as well as post-SFM dummy.

\section{Labour productivity as a dependent variable to spoilage rate}

The results in Table 4 show that spoilage rate has a statistically significant relationship with labour productivity as shown by its $t$-value of -4.555 . It is above the critical absolute $t$-value of 1.960 at the $5 \%$ level of significance (Curwin \& Slater 2002). The negative relationship indicates that any decrease in spoilage rate would result in an increase in labour productivity.

\section{Labour productivity as a dependent variable to absenteeism rate}

Results as illustrated in Table 4 show that absenteeism rate has a statistically significant relationship with labour productivity. This is determined by its $t$-value of 2.504 , which is above the critical absolute $t$-value of 1.960 at the $5 \%$ level of significance.

\section{Labour productivity as a dependent variable to housekeeping}

Table 4 show that housekeeping has no relationship with labour productivity. This is determined by its $t$-value of 0.839 , which is below the critical absolute $t$-value of 1.960 at the $5 \%$ level of significance.

\section{Labour productivity as a dependent variable to shop floor management dummy variable}

Results show that SFM has no relationship with labour productivity. This is determined by its $t$-value of -0.885 and is below the critical absolute $t$-value of 1.960 at the $5 \%$ level of significance, thus accepting the null hypothesis of no relationship between the two variables. It has the adjusted $\mathrm{R}^{2}$ of 0.868 . However, the serial correlation is high at 1.914 when compared to the standard value of 1.72 at the $5 \%$ level of significance (Curwin \& Slater 2002).

TABLE 4: Results for labour productivity as a dependent variable to absenteeism, spoilage, housekeeping, as well as post-shop floor management dummy.

\begin{tabular}{lccc}
\hline Regression & Coefficient & $\boldsymbol{t}$-statistic & Probability \\
\hline Constant $\left(\mathrm{B}_{\mathrm{o}}\right)$ & 2.843 & 0.711 & 0.492 \\
Spoilage rate & -0.791 & -4.555 & 0.001 \\
Absenteeism rate & 0.359 & 2.504 & 0.029 \\
Housekeeping rate & 0.134 & 0.839 & 0.419 \\
Pre and/or post dummy & -0.094 & -0.885 & 0.395 \\
$R$-squared & 0.803 & F-statistics & 25.636 \\
Adjusted $R^{2}$ & 0.868 & Sum of squares & 3.612 \\
Standard error of regression & 0.188 & Durbin-Watson statistic & 1.914 \\
\hline
\end{tabular}

Note: Regression data: 2009-2017 for 96 observations. The following OLS estimation is based on the equation: Labour Productivity $=\mathrm{B}_{0}+\mathrm{B}_{1}$ Absenteeism $+\mathrm{B}_{2}$ Spoilage + $\mathrm{B}_{3}$ Housekeeping $+\mathrm{B}_{4}$ Pre/Post Dummy. 


\section{Summary of results: Statistical tests and box plots for determining whether the normality and homogeneity of variances have been met}

This section analyses data using factorial designs. It incorporates box plots to determine whether the factorial ANOVA assumptions of normality and homogeneity of variance have been met. Porkess (2005) explains that the populations represented should be normally distributed (that is, the normality), making the mean an appropriate measure of central tendency. However, the homogeneity of variance indicates that the population from which the data are sampled should have the same variance.

The Bartlett's test was used to verify whether the variances were equal for all the samples (Curwin \& Slater 2002). Figure 1 shows the summary of the results from Bartlett's test for homogeneity of variances.

Table 5 presents detailed results of Bartlett's test for homogeneity of variances for labour productivity, spoilage rate, absenteeism rate as well as housekeeping.

The $p$-value in the Bartlett's test (at $p>0.05$ ) shows that the homogeneity of variance is violated. The $p$-value at 7.520 is above the significant level of 0.05 . Therefore, the variances are not equal, given the amount of variability in the variances that can naturally occur in the data. This is confirmed by Levene's test of equality, shown in Table 6.

Porkess (2005) defines Levene's tests of equality as an inferential statistic used to assess the equality of variance on different samples. In Levene's test of equality, the statistical

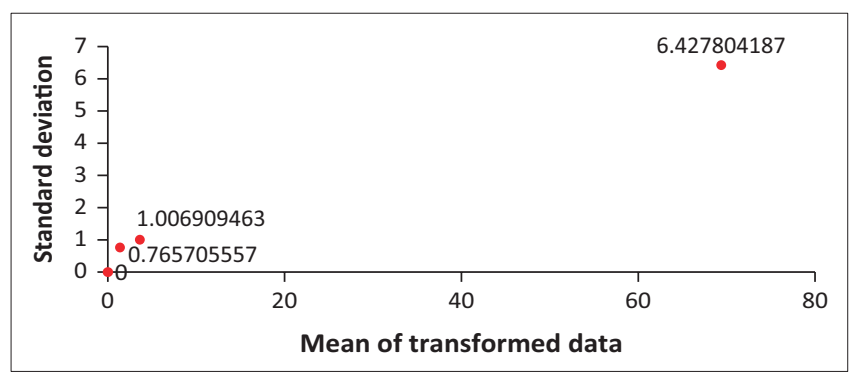

FIGURE 1: Bartlett's test for homogeneity of variances.

\begin{tabular}{lcc} 
TABLE 5: Bartlett's test for homogeneity of variances & $(p=7.520)$. \\
\hline Variables & $\begin{array}{c}\text { Means of transformed } \\
\text { data }\end{array}$ & $\begin{array}{c}\text { Standard deviations of } \\
\text { transformed data }\end{array}$ \\
\hline Spoilage & 1.369 & 0.766 \\
Absenteeism & 3.31 & 1.007 \\
Housekeeping & 69.375 & 6.428 \\
\hline
\end{tabular}

TABLE 6: Levene's test of equality of error variances.

\begin{tabular}{lcc}
\hline Fisher-Snedecor & $t$-statistic for equal means & Significance \\
\hline 0.282 & -0.489 & 0.604 \\
\hline
\end{tabular}

procedure assumes that variances of the populations from which different samples are drawn are equal. However, the results in Table 6 show that the obtained similarities between the variances in the samples between the pre and post data sets at $p$-value 0.604 did not occur. They are above the statistically significant value of 0.05 . The associated plots in Figure 2 confirm the results.

Figure 2 shows the mode of change from pre- to post-SFM system periods are homogeneous. However, the box plots indicate that the variances for spoilage, absenteeism and housekeeping rates are not equal. This was confirmed by both Bartlett's and Levene's tests results.

\section{Discussion}

This study investigates the influence of the SFM system on the improvement of labour productivity in an automotive parts manufacturing company in South Africa. It examined the production and related experience of the parts manufacturing company that has adopted an SFM strategy for its employees. Quarterly time series data on absenteeism, spoilage and housekeeping were used to analyse data. Results indicate that housekeeping and SFM have no relation to labour productivity. However, it revealed that the both the absenteeism and spoilage rates have a relationship with labour productivity. This is supported by Bhuvanaiah and Raya (2014) who indicate that, during the process of the SFM system, employees become self-motivated, driven and energised to perform to the organisation's expectations. Furthermore, Riegger (2011) adds that an engaged shop floor employee is aware of business context and works with colleagues to improve performance within the job for the benefit of the organisation.

\section{Implications of results for policy and practice}

Organisations in South Africa should revise their performance management systems and develop SFM strategies, policies and practices that help to achieve new business goals and support organisational and cultural change (Wranx 2016).

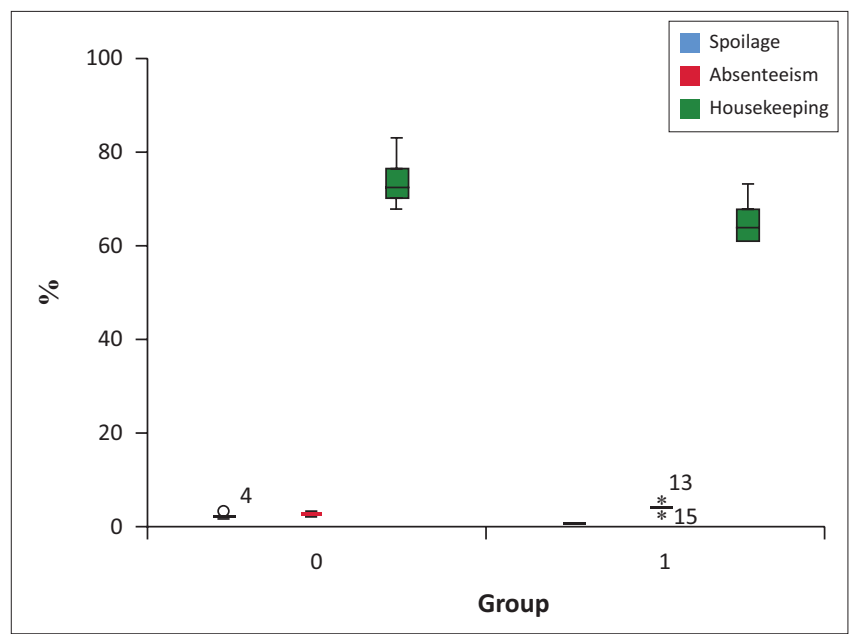

FIGURE 2: Box plots determining the normality and homogeneity of variance. 
This must be based on an understanding of the economic factors affecting employee engagement and motivation, and the significance of the psychological meaningfulness of work that influences shop floor employee engagement for productivity improvement. Besides the achievement of study objectives, the following conclusions can be made on the SFM philosophy:

- It is an extent of control that is exercised at the shop floor level for employee engagement aimed at achieving organisational values. Hence, SFM is a process for employee engagement gearing for organisational success through productivity.

- It empowers shop floor employees to make decisions and solve problems appropriate to their level in the organisation.

- It is a system that improves absenteeism and reduces spoilage rates for labour productivity.

- In order to maximise performance, a comprehensive performance policy must be developed, which aligns employee engagement to productivity (Farouk 2014).

\section{Study limitations}

The study was limited to an automotive parts manufacturing company within the eThekwini District Municipality. The investigation was conducted in a single company that has adopted the SFM system. As there are 378 registered automotive parts manufacturing organisations in South Africa (SAinfo 2008), the results cannot be extrapolated to other companies within the sector. Secondly, it did not examine the process followed during the SFM implementation including (among others) the individuals that participated in the implementation process. It only used quarterly time series data to determine the pre- and post-labour productivity effects resulting from the SFM strategy. Lastly, the econometrics model used was of the OLS variety, solely due to data constraints. Future studies ought to use the more advanced Johansen VAR methodology or panel data analysis, both of which rely on large data sets.

\section{Conclusion}

SFM is an appropriate employee engagement process that creates a working environment that encourages worker participation and commitment. Properly implemented and managed, the system results in employee performance improvement. Psychological meaningfulness and motivation play a role in shop floor employee engagement (Geldenhuys et al. 2014). Consequently, the study revealed the relationship between both absenteeism and spoilage rates and labour productivity in the selected automotive parts manufacturing company. It is an approach that takes advantage of a focused organisational strategy to combine employee communication, decision-making and participation. The system can be used for developing employee capability in the organisations. Hence, the employees will have the capabilities to solve organisational problems (Alazzaz \& Whyte 2015).

\section{Future research required}

During the course of this study, issues relating to the longterm survival of an SFM strategy after implementation were not covered. This includes the applicability of SFM to a wider sector of the economic activity, including the public sector. The nature of this research did not allow these areas to be covered in depth. It is recommended that future research should examine the following issues in greater depth:

- When to use and when not to use the SFM system.

- The applicability of an SFM approach to other industrial sectors.

- The process followed during the implementation of an SFM system.

- A more comprehensive investigation should be carried out using a randomised sample of the registered automotive manufacturers that use an SFM strategy, to see if the results can be generalised.

\section{Acknowledgements Competing interests}

The author declares that he has no financial or personal relationships that may have inappropriately influenced him in writing this article.

\section{Author's contributions}

The author, R.W.D.Z., declares that he is the sole author of this research article. He administrated the questionnaire, worked on the literature review, analysed the raw data, aligned and consolidated the article into a final manuscript.

\section{Ethical consideration}

This article followed all ethical standards for carrying out research.

\section{Funding information}

The article will be paid for by the researcher fund kept by the Durban University of Technology (DUT).

\section{Data availability statement}

Data sharing is not applicable to this article as no new data were created or analysed in this study.

\section{Disclaimer}

The views and opinions expressed in this article are those of the author and do not necessarily reflect the official policy or position of any affiliated agency of the author.

\section{References}

Alazzaz, F. \& Whyte, A., 2015, 'Linking employee empowerment with productivity in off-site construction Engineering', Construction and Architectural Management 22(1), 21-37. https://doi.org/10.1108/ECAM-09-2013-0083

Bersin, J., 2015, Becoming irresistible: A new model for employee engagement, viewed 19 September 2017, from www.dupree.deloitte.com. 
Bicheno, J., 1998, 'Your lean toolbox', Control, September, pp. 10-11.

Bhuvanaiah, T. \& Raya, R.P., 2014, 'Employee engagement: Key to organisational success', Journal of Indian Management 11(4), 61-71.

Business Victoria, 2016, Increase profitability and staff retention with an innovative culture, State Government of Victoria, Melbourne.

Brown, D.I., 1995, 'Team-based reward plans', Team Performance Management 1/1, 10, viewed 10 April 2018, from https://www.emeraldinsight.com/doi/ abs/10.1108/13527599510064940.

Bryman, A. \& Bell, E., 2007, Business research methods, Oxford Press, New York.

Cherry, K., 2016, What is self-determination theory? viewed 06 April 2017, from www. verywell.com.

Cohen, S.G. \& Bailey, D.E., 1997, 'What makes teams work: Group effectiveness research from the shop', Journal of Management 23(3), 1-52. https://doi.org/ $10.1177 / 014920639702300303$

Conference Board, 2015, Productivity brief 2015: Global productivity stuck in the slow lane with no signs of recovery in sight, Business World, New York.

Cook, S., 2008, The essential guide to employee engagement: Better business performance through staff satisfaction, 1st edn., Kogan Page, London.

Curwin, J. \& Slater, R., 2002, Quantitative methods for business decisions, British Library Cataloguing Data, London.

Dobre, O, 2013, 'Employee motivation and organisational performance', Review of Applied Socio-Economic Research 5(1), 1-8.

Farouk, I., 2014, 'Exploring employee attitude and productivity at an Electrical Company of Ghana, Ashanti-East', BSc Human Resource Management 5(4), 69-76.

Gallup, 2016, Gallup, viewed 11 June 2017, from www.q12.gallup.com.

Geldenhuys, M., Laba, K. \& Venter, C.M., 2014, 'Meaningful work, work engagement and organisational commitment', Journal of Industrial Psychology 40(1), 10 pages. https://doi.org/10.4102/sajip.v40i1.1098

Gems, E., 2015, New perspectives in employee engagement in human resources, UK: Emerald Group Publishing Limited, Bingley.

Guest, D., 2014, 'Employee engagement: A sceptical analysis', Journal of Organisational Effectiveness: People and Performance 1(2), 141-156. https://doi.org/10.1108/ JOEPP-04

Grundnig, A. \& Meitinger, S., 2013, 'Führung ist nicht alles - aber ohne Führung is alles nichts [Leadership is not everything - but without leadership everything is nothing]', Zeitschrift für wirtschaftlichen Fabrikbetrieb 108(3), 133-6. https://doi. org/10.3139/104.110908

Hanenkamp, N., 2013, 'The process model for shop floor management implementation', Advances in Industrial Engineering and Management 2(1), 40-46.

Hertle, C., Tisch, M., Klas, H., Metternich, J. \& Abele, E., 2016, 'Recording shop floor management competencies', A Guideline for the 49th CIRP Conference on Manufacturing Systems, 1(1), 625-630. https://doi.org/10.1016/j.procir.2016.11.108

Hirano, H., 1996, 5 S for operators: 5 pillars of the visual workplace (5S Shido Manual), Productivity Press, Tokyo.

Ho, S.K.M., 1997, 'Workplace learning: The 5-S way', Journal of Workplace Learning 9(6), 185-191. https://doi.org/10.1108/13665629710180375

Hoxsey, D., 2010, 'Are happy employees healthy employees? Researching the effects of employee engagement on absenteeism', Canadian Public Administration 53(1), 551-571. https://doi.org/10.1111/j.1754-7121.2010.00148.x

Illing, H., 2011, 'Production is king: Shop floor management', Management und Qualität 46(1-2), 8-10.

Illing, H., 2012, 'Shop floor-management: Besser führen in der Fabrik', Management und Qualität 47(9), 23-24.
Jiang, X., 2010, 'How to motivate people working in teams', International Journal of Business and Management 5(10), 223-229.

Klein, N., 2012, Real wage, labour productivity, and employment trends in South Africa, a closer look, IMF WP/12/92, International Monetary Fund, Washington, DC.

Larteb, Y., Benhadou, M., Haddout, A. \& Nahla, H., 2016, 'The key to lean performance: Implementing a daily shop floor control system using standardization and visual management', International Journal of Advanced Research in Management (IJARM) 7(1), 34-43.

Liker, J., 2012, The Toyota model: 14 principles that will make your business successful, 1st edn., McGraw-Hill, New York.

Mann, D., 2009,'The missing link: Lean leadership', Frontiers of Health Services Management 26(1), 15-26. https://doi.org/10.1097/01974520-20090700000003

Nyaoga, R.B., Simeon, K. \& Magunu, P.O., 2010, 'The effectiveness of performance', African Journal of Business \& Management (AJBUMA) 1(1), 123-134.

O'hEocha, M., 2000, 'A study of the influence of company culture, communication and employee attitudes on the use of 5Ss for environmental management at Cooke Brothers Ltd', The TQM Magazine 12(5), 321-330. https://doi.org/ Cooke Brothers Ltd', The TQM
$10.1108 / 09544780010341923$

Peters, R., 2003, Shop floor management: Lead at the place of value creation, 2nd edn., Ludeswig, Abbildungen.

Polster, A, 2013, Shop floor management: Introduction of shop floor management viewed 25 April 2018, from https://translate.google.co.za/translate? hl=en\&sl=de\&u=http://www.iapo-online.de/fileadmin/user_upload/documents/ PDF/iapo_AndreasPolster_2013.05.06.pdf\&prev=search.

Porkess, R., 2005, Collins internet-linked dictionary of statistics, Harper Collins, Glasgow.

Quddus, A. \& Ahsan, N., 2014, 'A shop-floor kaizen breakthrough approach to improve working environment and productivity of a sewing floor in RMG industry', Journa of Textile and Apparel Technology and Management 8(4), 1-12.

Riegger, M., 2011, 'Großer Qualitätssprung durch Shopfloor management', Maschinen Markt 5(27), 32-35.

Röhrle, J., 2009, 'Der Mensch imganzheitlichen Produktions system', in H. Bullinger, D. Spath, H. Warnecke \& E. Westkämper (eds.), HandbuchUnternehmensorganisation: Strategien, Planung, Umsetzung, 3rd edn., pp. 586-589, Springer, Berlin, Heidelberg.

SAinfo, 2008, South Africa's automotive industry, viewed 14 October 2017, from http://www.southafrica.info/doing_business/economy/key_sectors/ motorindustryboost.html.

Suzaki, K., 1993, New shop floor management: Empowering people for continuous improvement, 2nd edn., The Free Press, New York.

UNIDO, 2013, Sustaining employment growth: The role of manufacturing and structural change overview, Industrial Development Report 2013, United Nations, New York.

Womack, P, 2008, From modern management to lean management. In lean transformation summit, London, November 21, 2008, Lean Enterprise Institute, London.

Wranx: Effective Measurable Learning, 2016, Closing the feedback loop: Managing the performance of performance management, viewed 14 May 2018, from https:// blog.wranx.com/closing-the-feedback-loop-managing-the-performance-ofperformance-management.

Yin, R.K., 2008, Handbook of applied research: California, Sage, Thousand Oaks, CA.

Zahraee, S.M., Hashemi, A., Abdi, A.A., Shahpanah, A. \& Rohani, J.M., 2014, 'Lean manufacturing implementation through value stream mapping: A case study', Jurnal Teknologi 68(3), 119-124. https://doi.org/10.11113/jt.v68.2957 